\title{
Identification of cyclic hexapeptides natural products with inhibitory potency against Mycobacterium tuberculosis
}

\author{
Sheo B. Singh 1,4, Joshua Odingo ${ }^{2}$, Mai A. Bailey², Bjorn Sunde², Aaron Korkegian², Theresa O'Malley², \\ Yulia Ovechkina ${ }^{2}$, Thomas R. loerger ${ }^{3}$, James C. Sacchettini ${ }^{3}$, Katherine Young ${ }^{1}$, David B. Olsen ${ }^{1}$ \\ and Tanya Parish ${ }^{2^{*}}$ (1)
}

\begin{abstract}
Objective: Our aim was to identify natural products with anti-tubercular activity.

Results: A set of $\sim 500$ purified natural product compounds was screened for inhibition against the human pathogen Mycobacterium tuberculosis. A series of cyclic hexapeptides with anti-tubercular activity was identified. Five analogs from a set of sixteen closely related compounds were active, with minimum inhibitory concentrations ranging from 2.3 to $8.9 \mu \mathrm{M}$. Eleven structural analogs had no significant activity $(\mathrm{MIC}>20 \mu \mathrm{M})$ demonstrating structure activity relationship. Sequencing of resistant mutant isolates failed to identify changes accounting for the resistance phenotype.
\end{abstract}

Keywords: Mycobacteria, Antibacterial, Natural product, Anti-tubercular, Antibiotic resistance

\section{Introduction}

Tuberculosis remains a global health problem, with an increasing number of new cases (10.4 million in 2015) and an increasing problem of drug resistance [1]. New therapeutic agents which act against novel bacterial targets are needed to supplement and supplant the current drugs. Therefore there is great interest in finding new chemical matter that has activity against the causative agent, Mycobacterium tuberculosis. A large effort has been expended to examine small molecule libraries as starting point for drug discovery [2,3]. Less attention has been paid to natural products as starting points for a discovery program. We were interested in expanding chemical diversity to identify novel inhibitors which could be used either as starting points for a drug discovery program or as probes to identify novel targets.

\footnotetext{
*Correspondence: tanya.parish@idri.org

${ }^{2}$ TB Discovery Research, Infectious Disease Research Institute, 1616 Eastlake Avenue E, Suite 400, Seattle, WA 98102, USA

Full list of author information is available at the end of the article
}

\begin{abstract}
Main text
A phenotypic screen to identify compounds with activity against $M$. tuberculosis using the MSD collection of purified natural products was initiated. A small set $(\sim 500)$ of natural products for activity against $M$. tuberculosis H37Rv-LP (ATCC 25618) expressing a red fluorescent protein were tested [4-6]. Compounds were tested at a single concentration of $20 \mu \mathrm{M}$. Growth was measured by fluorescence after 5 days of aerobic culture in Middlebrook 7H9 medium supplemented with $10 \%$ v/v OADC (oleic acid, albumin, D-glucose, catalase; Becton-Dickinson) and $0.05 \% \mathrm{w} / \mathrm{v}$ Tween 80 at $37{ }^{\circ} \mathrm{C}$ in 384-well plates. Growth inhibition was calculated with reference to controls (DMSO only). Within this screen, hits were defined as having $>30 \%$ inhibition of growth. Hits were confirmed by testing compounds in a dose response, using two readouts for growth- $-\mathrm{OD}_{590}$ and fluorescence (Ex 560/Em 590) [4-6]. Compounds were solubilized in DMSO, and a ten point, twofold serial dilution prepared in DMSO. M. tuberculosis was cultured in Middlebrook 7H9 supplemented with $10 \% \mathrm{v} / \mathrm{v}$ OADC and $0.05 \% \mathrm{w} / \mathrm{v}$ Tween 80. Cultures were inoculated at a final $\mathrm{OD}_{590}$ of
\end{abstract}


0.02 into 96-well plates containing compounds (final DMSO concentration of 2\%). The starting concentration for compounds was $20 \mu \mathrm{M}$. Growth inhibition curves were plotted using the Levenberg-Marquardt algorithm and the concentration that resulted in $90 \%$ inhibition of growth was determined $\left(\mathrm{MIC}_{90}\right)$. For active compounds, assays were conducted at least twice. Rifampicin was used as a control in each plate-for comparison the MIC of rifampicin was $0.0077 \mu \mathrm{M}$.

From these experiments, MSD-453 confirmed as a hit and further analogs based on similarity searches were ordered and tested. The initial hit, a cyclic hexapeptide, cyclo[N-(Me)Phe-Pro-Phe- $N-(\mathrm{OH})$ Leu-Piz-Piz] (compound 1) had good activity against $M$. tuberculosis, with an $\mathrm{MIC}_{90}$ of $2.3 \mu \mathrm{M}$ (Table 1). Several natural congeners (2-4) and semi-synthetic and synthetic analogs (5-16) were available from the MSD sample library and were tested for activity against replicating $M$. tuberculosis under aerobic conditions in liquid medium. Structural identities and purity of the compounds were verified prior to anti-tubercular testing. Four other analogs (2-5) exhibited intermediate inhibitory potencies $\left(\mathrm{MIC}_{90}\right.$ of 2.8-8.9 $\mu \mathrm{M})$, whereas eleven compounds $(6-16)$ showed no inhibitory activity $\left(\mathrm{MIC}_{90}>20 \mu \mathrm{M}\right)$.

Although the dataset of compounds tested are limited, some elements of the structure-activity relationship (SAR) (Fig. 1) have been determined. Replacement of the $\mathrm{N}$-hydroxyleucine with $\mathrm{N}$-hydroxyisoleucine resulted in similar activity $\left(2, \mathrm{MIC}_{90}=2.8 \mu \mathrm{M}\right)$. Replacement of the phenylalanine with a valine reduced the activity slightly by three to fourfold $\left(3, \mathrm{MIC}_{90}=8.9 \mu \mathrm{M}\right)$. Similar reduced activity was seen after a double substitution of $N$-methylphenylalanine and phenylalanine with isoleucine and leucine $\left(4, \mathrm{MIC}_{90}=7.3 \mu \mathrm{M}\right)$. An $N$-alkyl-ketone in place of $\mathrm{N}$-hydroxyleucine was tolerated, but reduced the biological activity by threefold $\left(5, \mathrm{MIC}_{90}=8.2 \mu \mathrm{M}\right)$, demonstrating that the $\mathrm{N}$-hydroxyl group at that position is not critical. In contrast, the piperazic acids (Piz) were critical for activity of the molecule, since several tetrahydropiperazic $(\Delta \mathrm{Piz})$ acid derivatives $(\mathbf{6}-\mathbf{1 2})$ and the pipecolic acid (Pip) (13 and 15) analog resulted in loss of antitubercular activity. $O$-Alkylation of the $N$-hydroxyleucine with an acetic acid or acetic acid ester abrogated activity (13-14). The combined replacement of $N$-methylphenylalanine with norvaline and phenylalanine with leucine also removed activity $\left(\mathbf{1 6}, \mathrm{MIC}_{90}>20 \mu \mathrm{M}\right)$. Based on these analogs, we were able to determine some limited structure-activity relationship (Fig. 1). Although the compounds were not as potent as rifampicin, they did have good activity, with a dynamic SAR ranging from low micromolar to inactive $(>20 \mu \mathrm{M})$.

The original hit molecule, MSD-453, along with several congeners [7-10] and synthetic analogs [8-12], were
Table 1 Activity of cyclic peptides against $M$. tuberculosis

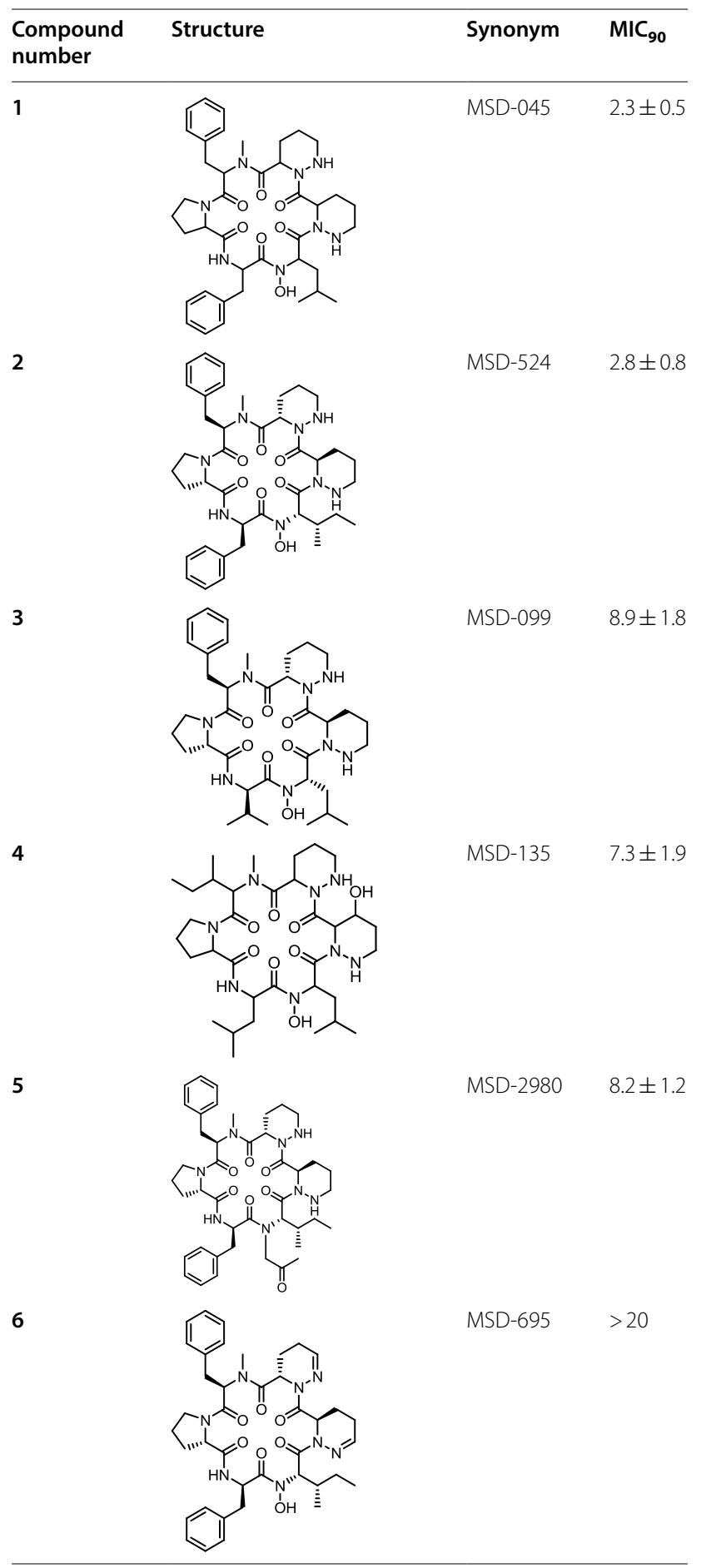

originally identified as sub-micromolar to low nanomolar oxytocin receptor antagonists. $M$. tuberculosis does not have a homolog of this receptor; thus, this series appears to have a different target in the pathogen. 
Table 1 (continued)

\begin{tabular}{llll}
$\begin{array}{l}\text { Compound } \\
\text { number }\end{array}$ & Synonym & $\mathrm{MIC}_{\mathbf{9 0}}$ \\
\hline
\end{tabular}

8

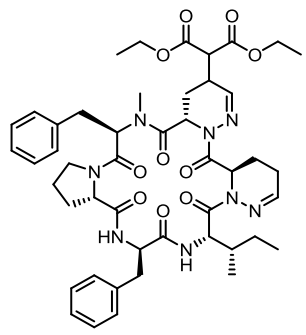

9<smiles>CCC(C)[C@@H](Cc1ccccc1)N[C@@H](Cc1ccccc1)C(=O)N1CCC[C@H]1C(=O)N1CCCN1C(=O)[C@@H]1CCC=NN1C(=O)[C@@H](Cc1ccccc1)N(C)C</smiles>

10

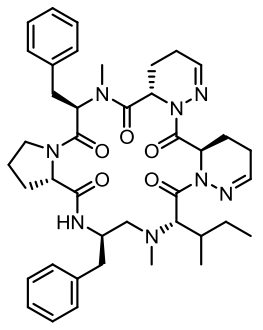

11<smiles>CC/C=N\CC(C=O)N(C=O)CC(C=O)NCC(O)C(Cc1ccccc1)NC(=O)C1CCCN1C(=O)C(Cc1ccccc1)N(C)C(O)CNC(CC)CC</smiles>

12

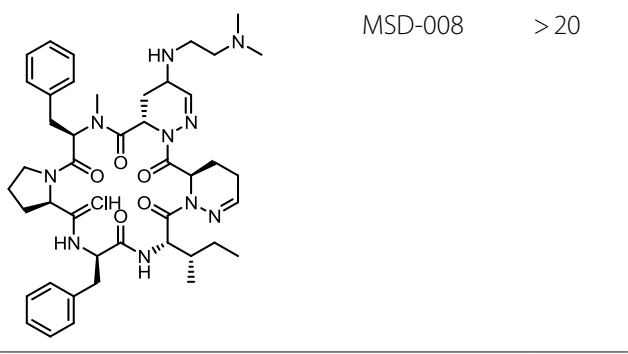

Table 1 (continued)

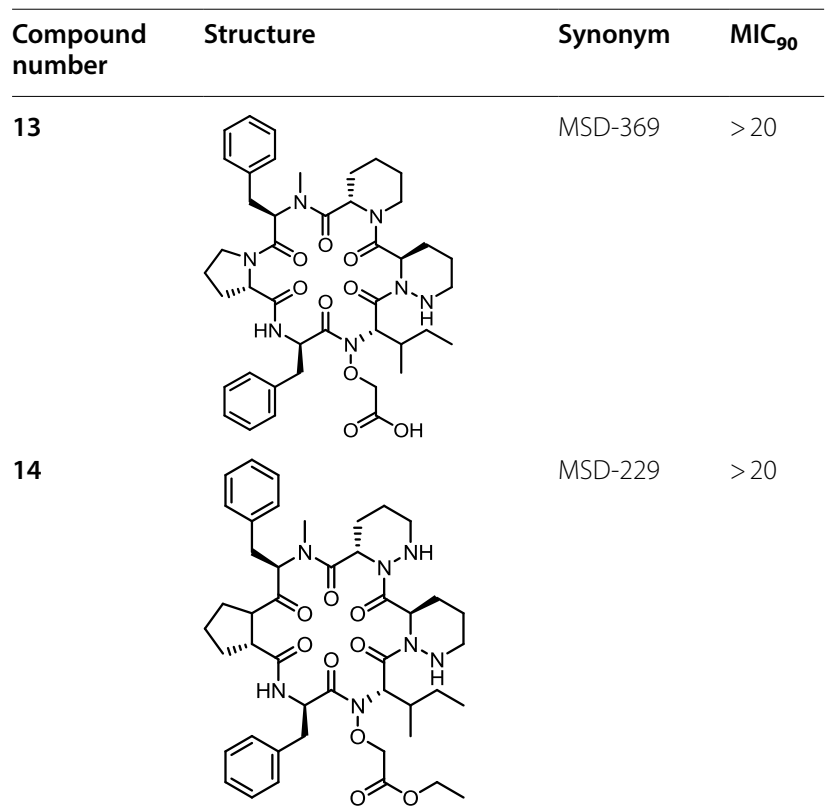

15

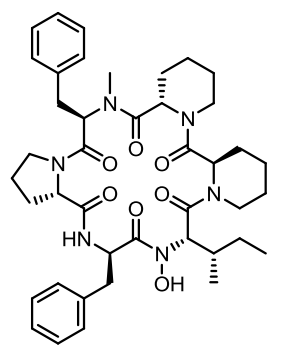

16<smiles>CCCC(C(=O)NC(C)C)C(=O)N1CCCC1C(=O)NC(CC(C)C)C(=O)N1CCCNN1C(=O)C(CC(C)C)N1NCCCC1C(=O)N(C)C(=O)C1CCCN1</smiles>

MSD-064 >20

$\mathrm{MIC}_{90}$ were determined against aerobically-cultured $M$. tuberculosis in liquid culture after 5 days of growth [5]. Growth inhibition curves were plotted using the Levenberg-Marquardt algorithm and the concentration that resulted in $90 \%$ inhibition of growth was determined $\left(\mathrm{MIC}_{90}\right)$. $\mathrm{MIC}_{90}$ were determined a minimum of two times for active compounds. Data are average \pm standard deviation

In an attempt to identify the $M$. tuberculosis biochemical target, resistant mutants to two of the compounds were isolated. The potency of each compound on Middlebrook 7H10 medium containing 10\% v/v OADC supplement was measured. $\mathrm{MIC}_{99}$ values were determined by the serial proportion method and defined as the minimum concentration required to prevent $99 \%$ growth on solid medium [13]. Under these incubation conditions, the $\mathrm{MIC}_{99}$ was 1.6 and $0.8 \mu \mathrm{M}$ for MSD-045 and MSD-099 respectively (Table 2). Resistant mutants 


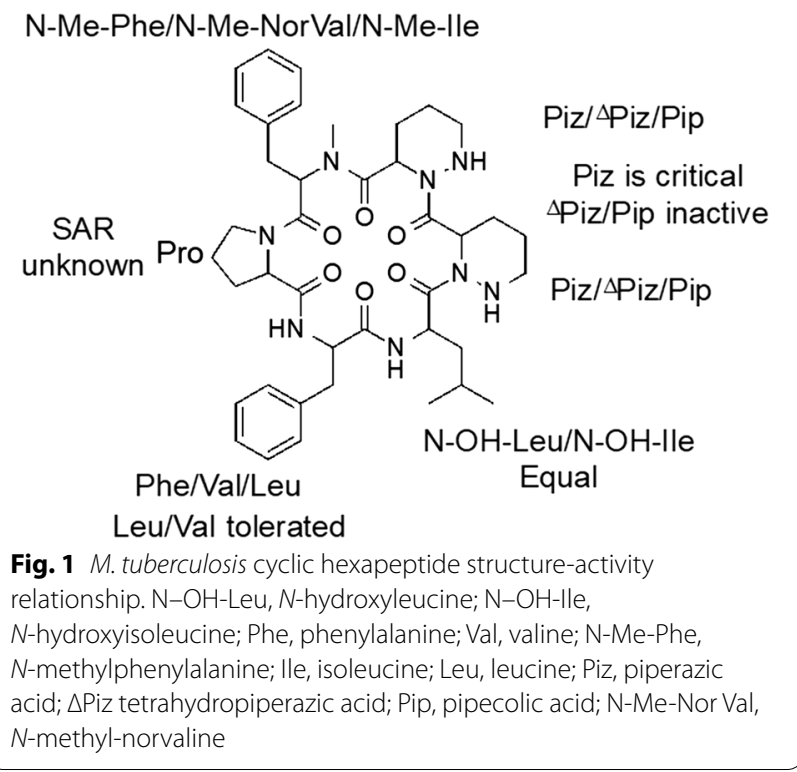

Table 2 M. tuberculosis strains resistant to hexapeptide inhibitor compounds

\begin{tabular}{lll}
\hline Strain & Compound & MIC $_{\mathbf{9 9}}(\boldsymbol{\mu M})$ \\
\hline WT & MSD-045 & 1.6 \\
LP-0458690-RM1 & MSD-045 & 13 \\
LP-0458690-RM2 & MSD-045 & 25 \\
LP-0458690-RM3 & MSD-045 & 25 \\
LP-0458690-RM4 & MSD-045 & 25 \\
LP-0458690-RM5 & MSD-045 & 25 \\
LP-0458690-RM6 & MSD-045 & 25 \\
WT & MSD-099 & 0.8 \\
LP-0458686-RM1 & MSD-099 & 3.1 \\
LP-0458686-RM2 & MSD-099 & 3.1 \\
LP-0458686-RM3 & MSD-099 & 3.1
\end{tabular}

$\mathrm{MIC}_{99}$ were determined against $M$. tuberculosis resistant isolates on solid medium after 3-4 weeks. MIC $_{99}$ was determined by the serial proportion method and defined as the minimum concentration required to prevent $99 \%$ growth [13]

were isolated on Middlebrook 7H10 plus 10\% v/v OADC at $5 \mathrm{X}$ MIC of each compound after 3-4 weeks growth [14]. Colonies were tested for $\mathrm{MIC}_{99}$ on solid medium to confirm resistance (Table 2). In this longer term assay on solid media both compounds showed better potency than when tested for shorter time (5 days) assay in liquid media (Table 1). Although nine confirmed resistant isolates were subjected to whole genome sequencing [15], no mutations were observed in 8 of the strains. Strain LP0458686-RM1 had two mutations, one in gap (Rv1436) and one in Rv1543, but these were not observed in any of the other eight strains. Thus no genotypic explanation for the observed resistance was determined. In this case, the resistance phenotype could be due to epigenetic phenomena.

In conclusion, a series of cyclic natural product peptides with activity against $M$. tuberculosis, which could form the basis of further exploratory work including target identification, are disclosed. Future work to identify the intracellular target would assist in further development of this class of molecules.

\section{Limitations}

- No in vivo activity is reported yet.

- The mode of resistance is not yet understood.

- The target for the series is not known.

\section{Abbreviations}

OADC: oleic acid, albumin, D-glucose, catalase; MIC: minimum inhibitory concentration; SAR: structure-activity relationship; Piz: piperazic acid; Pip: pipecolic acid.

\section{Authors' contributions}

Experimental design: SBS, JO, MAB, BS, AK, TOM, YO, TRI, KY, DBO, TP. Experimental work: MAB, BS, AK, TOM, YO, TRI. Data analysis: SBS, JO, MAB, BS, AK, TOM, YO, TRI, JCS, KY, DBO, TP. Writing manuscript: SBS. DBO, TP. Reviewing manuscript: All authors. All authors read and approved the final manuscript.

\section{Author details}

${ }^{1}$ Merck \& Co., Inc., Infectious Diseases, 770 Sumneytown Pike, West Point, PA 19486, USA. ${ }^{2}$ TB Discovery Research, Infectious Disease Research Institute, 1616 Eastlake Avenue E, Suite 400, Seattle, WA 98102, USA. ${ }^{3}$ Texas A\&M University, College Station, TX, USA. ${ }^{4}$ Present Address: SBS Pharma Consulting LLC, Edison, NJ 08820, USA.

\section{Acknowledgements}

We thank James Ahn and Juliane Ollinger for technical assistance. This work was carried out under the auspices of the TB Drug Accelerator consortium.

\section{Competing interests}

The authors declare that they have no competing interests.

\section{Availability of data and materials}

All data generated or analysed during this study are included in this published article.

\section{Consent for publication}

Not applicable.

\section{Ethics approval and consent to participate} Not applicable.

\section{Funding}

This work was supported in part by funding from the Bill and Melinda Gates Foundation under grant OPP1024038.

\section{Publisher's Note}

Springer Nature remains neutral with regard to jurisdictional claims in published maps and institutional affiliations.

Received: 14 May 2018 Accepted: 20 June 2018

Published online: 28 June 2018 


\section{References}

1. WHO. Global tuberculosis report 2017. ISBN 978-92-4-156551-6. 2017 http://www.who.int/tb/publications/global_report/en/. Accessed 22 June 2018

2. Kumar A, Chettiar S, Parish T. Current challenges in drug discovery for tuberculosis. Expert Opin Drug Discov. 2017;12:1-4.

3. Zuniga E, Early J, Parish T. The future for early stage tuberculosis drug discovery. Future Microbiol. 2015;10:217-29.

4. Carroll P, Schreuder LJ, Muwanguzi-Karugaba J, Wiles S, Robertson BD, Ripoll J, Ward TH, Bancroft GJ, Schaible UE, Parish T. Sensitive detection of gene expression in mycobacteria under replicating and nonreplicating conditions using optimized far-red reporters. PLoS ONE. 2010;5:e9823.

5. Ollinger J, Bailey MA, Moraski GC, Casey A, Florio S, Alling T, Miller MJ Parish T. A dual read-out assay to evaluate the potency of compounds active against Mycobacterium tuberculosis. PLoS ONE. 2013;8:e60531.

6. Zelmer A, Carroll P, Andreu N, Hagens K, Mahlo J, Redinger N, Robertson BD, Wiles S, Ward TH, Parish T, Ripoll J, Bancroft GJ, Schaible UE. A new in vivo model to test anti-tuberculosis drugs using fluorescent imaging. J Antimicrob Chemother. 2012:67:1948-60.

7. Goetz MA, Koupal LR, Schwartz CD, Liesch JM, Hensens OD, Anderson PS, Freidinger R, Pettibone DJ. Oxytocin and vasopressin antagonists. Google Patents; 1992

8. Pettibone DJ, Clineschmidt BV, Anderson PS, Freidinger RM, Lundell GF, Koupal LR, Schwartz CD, Williamson JM, Goetz MA, Hensens OD, Liesch JM, Springer JP. A structurally unique, potent, and selective oxytocin antagonist derived from Streptomyces silvensis. Endocrinology. 1989;125:217-22

9. Bock MG, DiPardo RM, Williams PD, Pettibone DJ, Clineschmidt BV, Ball RG, Veber DF, Freidinger RM. Receptor ligands which bind the oxytocin receptor with selectivity and high affinity. Chemical modification of a Streptomyces silvensis derived cyclic hexapeptide. J Med Chem. 1990:33:2321-3.

10. Williams PD, Bock MG, Tung RD, Garsky VM, Perlow DS, Erb JM, Lundell GF, Gould NP, Whitter WL, Hoffman JB, Kaufman MJ, Clineshcmidt BV, Pettibone DJ, Freidinger RM, Veber DF. Development of a novel class of cyclic hexapeptide oxytocin antagonists based on a natural product. J Med Chem. 1992;35:3905-18.

11. Bock MG, Freidinger RM, Tung RD, Veber DF, Williams PD. Cyclic hexapeptide oxytocin antagonists. Google Patents; 1993.

12. Williams PD, Anderson PS, Ball RG, Bock MG, Carroll L, Chiu SH, Clineschmidt BV, Culberson JC, Erb JM, Evans BE, Fitzpatrick SL, Freidinger RM, Kaufman MJ, Lundell GF, Murphy JS, Pawluczyk JM, Perlow DS, Pettibone DJ, Pitzenberger SM, Thompson KL, Veber DJ. 1-((7,7-Dimethyl2(S)-(2(S)-amino-4-(methylsulfonyl)butyramido)bicyclo [2.2.1]-heptan1(S)-yl)methyl)sulfonyl)-4-(2-methylphenyl)piperaz ine (L-368,899): an orally bioavailable, non-peptide oxytocin antagonist with potential utility for managing preterm labor. J Med Chem. 1994;37:565-71.

13. Sirgel FA, Wiid IJ, van Helden PD. Measuring minimum inhibitory concentrations in mycobacteria. Methods Mol Biol. 2009;465:173-86.

14. loerger TR, O'Malley T, Liao R, Guinn KM, Hickey MJ, Mohaideen N, Murphy KC, Boshoff HI, Mizrahi V, Rubin EJ, Sassetti CM, Barry CE 3rd, Sherman DR, Parish T, Sacchettini JC. Identification of new drug targets and resistance mechanisms in Mycobacterium tuberculosis. PLOS ONE. 2013:8:e75245

15. loerger TR, Feng YA, Ganesula K, Chen X, Dobos KM, Fortune S, Jacobs Wr J, Mizrahi V, Parish T, Rubin E, Sassetti C, Sacchettini JC. Variation among genome sequences of H37Rv strains of Mycobacterium tuberculosis from multiple laboratories. J Bacteriol. 2010;192:3645-53.
Ready to submit your research? Choose BMC and benefit from:

- fast, convenient online submission

- thorough peer review by experienced researchers in your field

- rapid publication on acceptance

- support for research data, including large and complex data types

- gold Open Access which fosters wider collaboration and increased citations

- maximum visibility for your research: over $100 \mathrm{M}$ website views per year

At $\mathrm{BMC}$, research is always in progress.

Learn more biomedcentral.com/submissions 